\title{
Harbouring Resilience and Hope: India's Encounter with COVID
}

Dr Neera Agnimitra ${ }^{+}$

\section{Abstract}

As India traverses its journey through the humongous COVID crisis, it has encountered the most distressing times. The two successive waves of the dreaded virus have wreaked havoc with the lives of people, causing surging infections, innumerable hospitalisations, and the most tragic loss of life. While the unprecedented economic and social disruptions caused by the contingency have been devastating for all, its most disproportionate impact has been borne by the impoverished and marginalised constituencies. Yet, amongst it all, the country and its people have demonstrated incredible grit and resolve to confront the odds. Compassion and camaraderie have prevailed, as the state and civil society have persevered to reach out in myriad ways to confront the disease and support those who have been impacted. Even though the crisis is far from over, and the imperative of extending the critical healing touch to scores of survivors takes centre space, hope abounds that India shall strive on and emerge stronger.

Keywords: COVID-19; Pandemic; Resilience; Hope; Response; Civil Society; India

\footnotetext{
${ }^{\dagger}$ Professor and former Head of the Department of Social Work, University of Delhi, India. Professor Agnimitra serves on International Board of Reviewers and Consultants of Space and Culture, India, Email: neeraagnimitra@gmail.com (C) 2021 Agnimitra. This is an Open Access article distributed under the terms of the Creative Commons Attribution License (http://creativecommons.org/licenses/by/2.0), which permits unrestricted use, distribution, and reproduction in any medium, provided the original work is properly cited.
} 


\section{Introduction}

From a phoenix burnt to ashes rises another, renewed and reborn. 2020 has been the year of the phoenix for India, a year of deep suffering brought by an unexampled pandemic, a year that locked humanity's mental energies into a fire spiral of uncertainty and despair but also a year that unlocked new levers of human resolve and economic resilience (Kadyan and Rajkumari,2021).

The world has been braving one of the gravest onslaughts on humankind ever since the dreaded novel Coronavirus 2019 (COVID-19) emerged and spread its tentacles across the globe with an alarming alacrity. It has now been more than one year and two months since the World Health Organization (WHO) declared this hitherto unprecedented contingency as a pandemic. The first wave of the pandemic hit the world hard as countries reeled under massive infection surge and fatalities. Irrespective of economic strength and medical prowess, nations of the world went through the most distressing times. As news of crippling medical crisis and fatalities trickled in from across, the world seemed to be at a complete loss to contain the virus and manage the monumental economic, social, and psychological ramifications of this harrowing pandemic.

\section{India's Response to COVID-19}

India's response to the initial outbreak of COVID19 received mixed reactions. While some, including the WHO appreciated the country's response by way of a complete nation-wide lockdown for more than five weeks and curtailment of travel to and from the country, many from within the country were harsh in critiquing the government for its insensitive approach to the scores of the impoverished and marginalised individuals and groups who were left without adequate recourse to survival wherewithal. However, given the humongous risk of spread of the highly infectious virus to the country's huge population, the options with the government were few and limited. The most critical consideration that augured in the frame related to 'flattening the epidemical curve'. As the country was encountering an unprecedented contagion with unknown dimensions, its public health infrastructure was grossly inadequate to respond to the serious threats that the virus represented. In effect, and as has been widely acknowledged, the lockdown gave the muchneeded time to the country to gear up in terms of preparedness and response.

The COVID crisis taught the country the biggest and the harshest lessons in sociology and economics. As the chronic and deeply embedded structural inequities surfaced, the country was made aware of sheer hand to mouth daily remit of the masses of its people. The sudden lockdown wreaked a disproportionately adverse impact on the country's mammoth impoverished and marginalised population comprising the urban migrants, informal workers, daily wage earners, and others who faced debilitating adversity emanating from closure of work places; job loss; curtailment of livelihood; homelessness; destitution; hunger and lack of access to basic provisions, safety protocol and health care. With no recourse to social security, their pain and suffering knew no bounds. Article after article and relentless media coverage was not able to capture even a fragment of the untold trauma that came their way. Lack of preparedness in the realm of disaster management was unceremoniously brought to public realm and to the attention of the state.

The rude shock managed to shake the administration into hastily garnering a response. The central and state governments reached out to provision food, rations, healthcare assistance, shelters and direct transfers through the Pradhan Mantri Garib Kalyan Anna Yojana (Food Scheme); Atmanirbhar Bharat; PM Kisan Scheme for farmers; wage increase for daily wagers; ex gratia payment for elderly, widows, women Jan Dhan holders and PwDs; medical insurance for health care workers; among others. Economic stimulus measures like relief for the MSMEs(Micro, Small \& Medium Enterprises) and 
NBFCs (Nonbank Financial Companies) were also rolled out in due course of time. The judiciary responded by way of directing the state to gear up its relief and response for the worst impacted constituencies. The corporates also mobilised by way of provisioning rations, medical equipment; protective gear; contributions to PM Cares Fund/ Chief Minister Funds and addressing basic needs of the communities. The civil society rose to the occasion and worked with exemplary spirit to extend a helping hand to the state to manage the humanitarian crisis. Peoples' organisations, voluntary organisations, faith-based congregations, youth groups, resident welfare and citizens groups and even individuals in their own right stood up and stood firm to offer assistance on the ground. Ordinary Indians interspersed with medical professionals and frontline workers to diversify the mantle of COVID warriors

As India trudged along in its journey in the last year and during the beginning of this year, it steadily gained lost ground in its own unique way. It showed remarkable resilience, both in fighting the virus, in building a spirit of community (that was rapidly getting depleted due to fear, stigma, and mistrust); and even in ensuring a measure of economic recovery. The period after the first wave was utilised to ramp up its essential clinical and testing infrastructure and undertake the manufacture of testing kits and core safety and protective gear. As country after country was forced to seek relief and aid from global repositories, India was quick to discern the need to garner self-reliance in its health-related supply chains. An augmentation of hospital beds and critical care infrastructure was undertaken. A significant achievement was the early breakthroughs in the development of vaccines, both within the global and domestic contexts, leading to the timely initiation of India's vaccination drive in January 2021. With the Oxford Research Group's Covishield, coproduced by AstraZeneca and the Serum Institute of India and the indigenous vaccine, Covaxin, developed by Bharat Biotech, India became a trendsetter of sorts in the domain of vaccine development and administration, as it strove to cover its frontline health and medical workers. The Aarogya Setu framework and the CoWin application consolidated the country's fight against COVID. Developed by the Government of India to connect essential health services with the people of India, the Aarogya Setu App was aimed at augmenting the initiatives of the Department of Health to reach out to people proactively and orient/update them about self-assessments, hotspots, risks, best practices and relevant advisories pertaining to the containment of COVID-19. Co-WIN, an innovative digital platform was created for realtime monitoring of COVID-19 vaccine delivery. It is currently playing an instrumental role in the registration of beneficiaries and delivery of vaccines across the length and breadth of the country since the second phase of COVID-19 vaccination commenced in March 2021.

However, just when we thought that worst was behind us and the gloom of the initial crisis had paled, the second wave of the Covid-19 pandemic pushed India to the brink of despondency and despair. Catching the state and citizenry unawares, it assumed phenomenal proportions as it ravaged state after state. As younger Indians who were largely unaffected in the first wave became casualties of this more virulent mutant, India confronted a crisis of unparalleled dimensions. A little over a month ago, on 07 May 2021, India recorded the highestever surge of 0.414 million COVID cases in a single day. That is when the devastating second wave of COVID peaked in the country. In a great sigh of relief, India seems to have surmounted the second wave, and in the present (as of 14 June 2021), almost an $85 \%$ decline in daily new cases has occurred, with India reporting 60,471 fresh cases (the lowest since 01April, 2021). Its weekly positivity rate is down to just $4.8 \%$ as compared to $21.4 \%$ between $4^{\text {th }}$ May and $10^{\text {th }}$ May, 2021 (Precautions Key, Warns Govt., 2021).

India's journey through the last year to the present time has been arduous, to say the least. Yet, it has demonstrated to its own people and those who watch India keenly from the sidelines, the resilience that this country and its people are capable of. The Economic Survey 2020-21 had acknowledged the path traversed by the country 
in controlling the pandemic and cushioning the economic impact when it applauded "the resolve exhibited by each Indian in finding its way out from the darkness of lives vs. livelihoods' to the glow of '\#Saving Lives And Livelihoods'" (Jain \& Chowdhri, 2021). The resilience of India's economy to rise from a sharp reduction of 23.9 per cent in the first quarter of 2020-21 was also validated by appraisals by the IMF.

The crisis brought forth stories of the exemplary human spirit of grit and compassion demonstrated by the tireless crusade against the pandemic by India's frontline COVID-19 warriors. Whether it was in the instance of the national lockdown wherein people upheld the power of self-belief; tenacity, discipline and steadfastness in responding to stern government regulations and advisories, or during the fatal second wave, when India stood afloat through countless acts of kindness, amplified on social media platforms like Facebook, Instagram, Twitter and messaging app WhatsApp, as requests and responses/ verified leads for hospital beds, medicines, injections, plasma, and oxygen availability flew back and forth incessantly, and help and solace continued to be offered.

When the entire world seemed to be painting a very grim context for India, hope and resilience continues to be proffered. Portals, helplines and help desks have sprung up, offering critical information, relief, and resources to the impacted. Virtual communities have stepped in to become temporary healthcare support systems. Notwithstanding its propensity to harbour myths and misconceptions, the social media and its Netscape continues to vibrate with humanity and compassion in these vastly turbulent times. The way people have displayed an uncanny ability to uphold self-belief in a time of immense uncertainty bespeaks the intrinsic strength of the Indians to rise to the occasion. It symbolises a level of resilience and grit that Indians have demonstrated in dealing with adversity of such monumental proportions. Although the country has been faced with a huge scarcity of core resources such as oxygen, medications, injections, hospital beds, ventilators and critical care infrastructure, citizens and their organisations have galvanised to support the patients and their families. Temporary COVID care centres have sprung up in stadia, cantonment areas, open grounds, hotels, academic institutions and even in railway coaches. Innovative support through oxygen langars; supply of cooked meals by families and neighbourhoods; provision of medical kits to COVID impacted families; and preparation and publicity of state-wise inventories of critical resources and services was offered. The spirit of voluntarism was fostered by a multi-hued cadre of human service providers. Resources were transported to provide reprieve for the many who struggled against a still tardy health care system.

Despite a slow rollout and the fact that the percentage of the total population covered by vaccines is less than that deemed imperative, going by sheer numbers, India is emerging as the fastest vaccinating country in the world, surpassing even the US (Covid: India Surpasses US, 2021). This is by no means a mean achievement. According to the Government of India vaccine tracker on CoWin, on 15th June 2021 more than 250 million $(25,90,44,072)$ doses of COVID-19 vaccine have been administered in the country. India has also crossed the "historic landmark" of 200 million $(20,46,01,176)$ first dose administration. Cumulatively, 4,00,31,646 people across the country have received their first dose and $6,74,499$ their second dose since the start of Phase- 3 of the vaccination drive.

Indeed, the COVID-19 global health contingency and its economic and psycho-social impacts have disrupted almost all aspects of life for all groups in society. It has dismantled the trajectory of motion of humankind, bringing life to a grinding halt. As the wheels of time have started moving once again, fear and pessimism about an uncertain future is still writ large. For the innumerable people and families who have suffered life-altering setbacks and losses of life of dear family members and loved ones, completion will not come easily. While the state is cognisant about its obligations of drawing a 
balance between augmenting public health and economic considerations and allocating largescale economic stimulus packages across different sectors and beneficiaries, the civil society shall have to provide the much needed 'human touch'. As small businesses struggle and even 'go under'; as families struggle to cope with the loss of loved ones and economic despondency arising out of loss of incomes and inflated healthcare expenses; as youth face bleak prospects for education and employment, human trauma is expected to mount in the impending times. The crisis is not over yet. Among fears of another crippling third wave, India will have to buckle up to embrace the griefstricken and those 'on the brink'. Communities will have to be reinvented and diffused with social capital. Institutional responses will have to be evolved and consolidated to support the abandoned and the forlorn. The imperative to 'disaggregate' and reach out to the 'individual' fighting a grim battle is crucial. The need to 'hand hold' the person requiring life preserving support, catharsis, consolation, succour, and comfort is immense. The country does not have the requisite number of trained mental health professionals, so members of the civil society will have to double up as responders performing myriad roles. As anxiety, depression, pain, anger, loneliness, stress and hopelessness abounds, shared spaces, by way of self-help and support groups, both virtual and real, will have to be created for people to catharsis, share, de-stress, 'reach-out to' and 'hold on to'. Care and protection of the vulnerable, including children, elderly, those with severe co-morbidities, pregnant women and informal workers, will also require concerted foresight and committed action.

\section{Towards Resilience and Hope}

During the testing times of the pandemic, India has emerged as a symbol of resilience and hope. Its collective resolve to fight is visible in the efforts of the millions of real-life heroes, those who are clad in white coats; and those who do not need white coats to perform acts of heroism and service. As hope resounds, we feel more certain that...this too shall pass, and India will emerge more assertive on the other end.

\section{References}

Covid: India surpasses US to become fastest vaccinating country in the world. (2021, 07 April). The Times of India. https://tinyurl.com/f4x7spwx

Economic Survey (2020-21). Ministry Of Finance. Government of India.

https://www.indiabudget.gov.in/economicsurv ey/

Jain, S. \& Chowdhri, S. (2021, 29 January). Resilient India fends off pandemic blow. Business Line, The Hindu. https://tinyurl.com/kee6rmbu

Kadyan, Sanjana and Rajkumari, Tulsipriya (2021, 30 January).Indian economy and the possible trinity of resilience. Financial Express. https://tinyurl.com/cztp8jn6

Precautions key, warns government as positivity rate declines to $4.8 \%$. (2021, 16 June). Times of India, p. 10. 